\title{
Fundar la Asociación de Editores independientes de Chile: una estrategia de resistencia colectiva ${ }^{1}$
}

\section{La création de l'Association des éditeurs indépendants au Chili: une stratégie de résistance collective}

\section{Contanza Symmes Coll}

École des hautes études en sciences sociales. CSE-EHESS, París conysymmes@gmail.com

\begin{abstract}
Resumen
La emergencia de la edición independiente, en los años noventa, coincide en Chile con la llamada vuelta a la democracia. A su vez, en el espacio editorial internacional, se encuentra inscrita al interior de un proceso de reorganización profunda del paisaje del libro, que exhibe al mismo tiempo movimientos de fuerte concentración junto con el surgimiento continuo de proyectos editoriales "alternativos". El objetivo de este artículo es mostrar cómo y bajo qué condiciones los modos organizativos desplegados por los editores independientes chilenos, sus dinámicas de asociatividad a diferentes niveles, la internacionalización de su discurso así como su accionar público, corresponden a una estrategia de resistencia colectiva frente a un fenómeno de globalización editorial.
\end{abstract}

Palabras Clave: Edición independiente, asociatividad, resistencia, globalización editorial, internacionalización.

\section{Résumé}

Lessor de l'édition indépendante au Chili dans les années 1990 Coöncide avec ce que l'on a appellé le retour à la démocratie. Ce mouvement s'inscrit à l'intérieur d'un processus de transformation profonde du paysage éditorial international, caractérisé à la fois par des mouvements de forte concentration et par l'apparition

\footnotetext{
1 Agradezco la lectura y los acertados comentarios de Juan E. Serrano- Moreno, Valentina Fazio y Jörg Stippel, los cuales ayudaron a mejorar la versión original de este texto. Este artículo está dedicado a Carolina Riachi, agradeciendo su amistad, su generoso hogar de largos mates y el canto del arroyo, que me acogieron cálidamenteen Alta Gracia, Córdoba, durante una etapa fundamental para mi trabajo de tesis.
} 
continue de projets éditoriaux “alternatifs". En étudiant les modes organisationnels des éditeurs indépendants au Chili, leur dynamique associative à différents niveaux, l'internationalisation de leurs discours ainsi que les modalités de leur action publique, cet article s'attache à montrer comment, et à quelles conditions, leur mouvement correspond à une stratégie de résistance collective face au phénomène de globalisation éditoriale.

Mots Clés: Édition indépendante, associativité, résistance, globalisation éditoriale, internationalisation.

El nuevo paisaje global del libro que comienza a dibujarse en los años ochenta, fraguado al calor de profundas mutaciones políticas y económicas, se destaca por la coexistencia simultánea de una fuerte concentración, con un fenómeno de emergencia de proyectos editoriales alternativos que no han cesado de aparecer. En Chile, los editores independientes constituyen un actor cuya emergencia, conformación, modos organizativos y denominación, se encuentran emplazados en un escenario multidimensional, que requiere ser abordado teniendo en cuenta, al menos, dos ejes. Estos son: a nivel local, un contexto sociopolítico y económico de carácter más rígido $^{2}$ dado por la transición y en su componente internacional, un esquema -que podríamos calificar como más flexible- en que los intercambios comerciales se han multiplicado, los flujos de información aumentan y la circulación internacional de ideas (Bourdieu, 2002; Dezalay, 2000) funciona a escala global.

En el plano político, las últimas décadas se han caracterizado por un fenómeno extendido de recuperación de la democracia que abarcó España, Grecia, los llamados países del Este - con la caída del muro de Berlín- e igualmente América Latina, al ponerse fin a las dictaduras del cono sur. Estas grandes transformaciones constituyen antecedentes que permiten explicar una intensificación en los intercambios comerciales, la cual, a pesar de ser considerable, no ha producido variaciones en la manera asimétrica en que transitan los bienes culturales, aunque los centros hayan podido diversificarse y las periferias se hayan complejizado.

Eso que llamamos globalización "lejos de abrir un espacio de circulación libre, consiste en una lucha por la redefinición de los territorios de distribución de productos culturales" (Sapiro, 2009). Los flujos de intercambios entre distintos territorios, en el caso del libro, se encuentran determinados por un conjunto de

2 Hablamos de un contexto rígido, al considerar la presencia determinante de un repertorio de obstáculos que Manuel Antonio Garretón ha definido como enclaves autoritarios y la preeminencia de un modelo económico neoliberal heredado, y posteriormente consagrado por los gobiernos democráticos. Aunque constituye uno de los dos ejes en que se sitúa el actor que analizamos, para efectos de este artículo no profundizaremos en el proceso transicional. 
factores complejos: una organización del mercado en áreas lingüísticas, la existencia de zonas geográficas en las cuales se inscriben los países y sus industrias culturales (como también la dirección que muestran estos flujos), todo lo cual se ha expresado en una recomposición del espacio editorial.

En efecto, si bien la internacionalización del mercado editorial no es nueva, ha conocido una aceleración considerable en el período que acabamos de mencionar; destacándose por una concentración creciente de los sellos, los cuales son adquiridos en operaciones de compra y/o fusiones trasnacionales. Este proceso de reordenamiento del mercado mundial del libro ha puesto en evidencia la fragilidad de las industrias editoriales en los países con débiles políticas culturales en el ámbito del libro. Un ejemplo contrario es el rol predominante que ha jugado la industria editorial española en el mercado del libro hispanoamericano. Ello se explica, en gran parte, por las medidas de fortalecimiento y promoción impulsadas por los gobiernos postfranquistas a partir de los años ochenta, las cuales develan el tipo de intercambio comercial que ésta mantiene con América Latina en sus distintas versiones locales ${ }^{3}$.

España exporta a América Latina US 340 millones en libros, mientras que toda ella no alcanza a exportar más de US 10 millones a España ${ }^{4}$, constituyendo uno de los problemas principales la incorporación al mercado de los derechos de autor. Antonio Ávila, director ejecutivo de la Federación gremial de Editores de España, en un encuentro entre el sector del libro de Chile y España celebrado en 2002 en Madrid, planteaba una evaluación lapidaria respecto del rol jugado por los gobiernos latinoamericanos en esta área: "No hay industria editorial latinoamericana y esto no es la consecuencia de la industria editorial española sino de políticas públicas erróneas que han sostenido los gobiernos latinoamericanos en su conjunto, son ellos los que han aniquilado la industria latinoamericana" (Aguilera, 2002, p. 26).

Esta declaración enuncia las relaciones que mantienen el Estado y los agentes privados de la cultura en un país central en el concierto del libro hispanoamericano. Resulta particularmente interesante puesto que quien la pronuncia es un dirigente gremial, bajo una posición sustentada en la rehabilitación de los poderes públicos, en su función de resguardo y promoción de la producción cultural. La situación de asimetría en los intercambios editoriales norte/sur, que les ha ido destinando a un rol de simple receptores, así como la necesidad de contar con una industria editorial nacional, comportan dos de las dimensiones centrales en que se sostiene el discurso de los editores independientes chilenos.

3 En un panorama general de asimetrías, las industrias editoriales de México, Argentina o Chile presentan ocupan posiciones distintas, debido -entre otras causas- al tamaño de sus mercados internos.

4 Fuente: Entrevista con profesional de ProChile, julio, 2009. 


\section{LOS EDITORES INDEPENDIENTES CHILENOS: EMERGENCIA, CONSTITUCIÓN Y ACCIONAR POLÍTICO DE UN ACTOR CULTURAL}

Pocos actores culturales de la historia reciente han logrado una visibilidad y capacidad de impulsar debates en la agenda pública chilena, comparable a la de los editores independientes. Aquí nos interesa objetivarlo como un hecho social, retrasando con este fin las condiciones de posibilidad que dibujaron el terreno en donde éstos se posicionan, a partir del cruce entre las lógicas de la producción simbólica y la de la internacionalización.

La edición es un lugar cuya función excede la simple fabricación de libros ${ }^{5}$, constituye un espacio de luchas entre agentes que mantienen diferentes relaciones con el poder y donde se cruzan variadas dimensiones de la vida social (Bourdieu, 1991). Es bajo esta óptica que entendemos los desplazamientos de los editores independientes, como una relación permanente de "trade-off" con los poderes públicos basada en estrategias que buscan permear la agenda política de la cultura. Se trata de estrategias que se apoyan en la internacionalización como fuente de legitimidad. Apropiándose de un concepto internacional como es la diversidad cultural -el cual traducen a la esfera local- apuestan a dinamizar el debate, empujando de esta forma a un diálogo entre los campos cultural y político.

A lo largo de estos últimos veinte años, el mundo de la edición independiente se fue conformando en un polo organizado que ha contribuido a transformar significativamente el espacio editorial nacional. Más aun, la trayectoria seguida por la Asociación de Editores independientes de Chile $^{6}$ constituye una puerta de entrada pertinente para analizar los reordenamientos que se han producido sobre una escena cultural más larga. Bajo esta perspectiva, examinamos los modos organizativos desarrollados, los principales ejes que hilvanan sus discursos y las dinámicas de su intervención pública.

Estamos hablando de un sector, correspondiente a un conjunto de estructuras editoriales pequeñas y medianas, que se definen fundamentalmente bajo la noción de "independencia" para diferenciarse de los grandes grupos. A su vez, comparten ciertas características de tamaño, modo de funcionamiento, espectro de géneros que

5 Constituyeun terreno donde se cruzan diversas dimensiones de la vida social, como son: el sistema de educación, las políticas públicas para el libro y la lectura, la regulación de los llamados bienes simbólicos, los derechos de autor, los grados de internacionalización de la producción editorial nacional, el lugar que ocupa el libro dentro de la economía de un país, etc. Si tomamos en cuenta las condiciones sociales que hacen posible su existencia, tenemos que esta revela, por una parte, de qué manera se distribuyen los capitales culturales en un país y por otra, estrechamente ligada a la primera, los grados de mayor o menor desigualdad en el acceso a la cultura impresa en una sociedad determinada.

6 En adelante EDIN. 
conforman su catálogo ${ }^{7}$ como de la manera en que se definen: a partir de un proyecto editorial concebido como crítico. Su quehacer se centra fundamentalmente en la publicación de textos pertenecientes a las Ciencias sociales, Historia, Literatura y ensayo, Estudios culturales, Estudios de género y textos académicos especializados; la reedición de autores nacionales y latinoamericanos, el rescate de obras de autores nacionales olvidados, de clásicos del pensamiento social universal y el hecho de consagrar una parte destacada de su fondo editorial a la Poesía.

Sus líneas editoriales presentan una coherencia interna. Mantenidas en el tiempo, son sustento de nichos editoriales tácitamente repartidos que han ido conformando una expertise particular. De esta manera, contribuyen a asegurar un cierto pluralismo dentro del repertorio editorial nacional, ofreciendo una franja de obras que no podrían existir dado su bajo interés comercial para el campo de la gran producción. La "independencia"» se erige aquí fundamentalmente respecto a los grandes grupos editoriales, a la capacidad de decidir sobre los géneros a publicar ya los contenidos que se ponen en circulación.

Desde el punto de vista de la función que cumple su catálogo, tenemos que junto con constituir un vivero de autores emergentes, éste pone a disposición un acervo de debates sobre la realidad social, política y cultural, "haciendo circular los trabajos de expertos o de contra expertos para favorecer el desarrollo de una 'experticia ciudadana', entregando elementos para animar los debates públicos" (Douyère y Pinhas, 2008, p. 76). Bajo un discurso que asigna un espacio de relevancia a la idea de construcción de una "ciudadanía crítica" son publicadas un conjunto de obras que abordan temáticas como: la transición, la memoria, los pueblos originarios, el patrimonio cultural, el modelo económico chileno, el sistema de educación, literatura de mujeres u otros sujetos de la historia reciente producidos por académicos e intelectuales nacionales, a su vez, considerados como "críticos" del cuadro económico y político actual. La edición independiente puede ser leída entonces desde una función garantizadora de un cierto pluralismo ${ }^{9}$ frente a la uniformización de la información y los debates públicos.

7 Que a la fecha exhibe 4000 títulos. Fuente: Prospecto Editores Independientes, 2010. Consultado en www.lom.cl el 15.11.2010.

8 Bertrand Legendre (2007) propone tres dimensiones para analizar la noción de independencia de un editor. Éstas son: la independencia editorial (capacidad de decidir qué se publica), la independencia financiera (referida al control total del capital y de las decisiones a este respecto) y la independencia comercial (ligada al control sobre el proceso de difusión y distribución); designando como independencia absoluta la condición que reúne los tres aspectos anteriores.

9 Un elemento a sumar a este respecto está dado por la situación de los medios de comunicación (nos referimos particularmente a la prensa escrita, aunque la situación de la televisión no es muy diferente) que se caracteriza en Chile por una concentración extrema, dificultando de manera ostensible la circulación de información diversa y de calidad y con esto, la generación de condiciones mínimas para la emergencia de opinión y debate ciudadanos. Véase el artículo de Juan Pablo Cárdenas (2006). 


\section{ALGUNAS PROPIEDADES CONSTITUTIVAS}

Si nos referimos a algunos de los elementos que bosquejan el perfil de estos editores ${ }^{10}$, vemos que: en su mayoría crearon sus proyectos editoriales en los años noventa, poseen diplomas universitarios (estudios formales), manejan idiomas extranjeros y fueron construyendo una relación con el mundo intelectual y académico del progresismo. Otra característica presente es que el trabajo editorial constituye su principal (sino única) fuente de ingresos ${ }^{11}$, lo que les diferencia de otros pequeños editores que publican de forma esporádica, realizando otro trabajo paralelo como fuente de subsistencia y elaborando libros de manera semi artesanal, en tirajes muy bajos, como es el caso - por ejemplo- de varios de los miembros del colectivo La Furia del libro ${ }^{12}$. No es precisamente un carácter artesanal del oficio de editor, aquello que los editores que hacen parte de EDIN han querido poner al centro de su identidad. Todo lo contrario, han ido formalizando cada vez más su quehacer (a través de la implementación de dispositivos institucionales: comités de lectura, encargados de colección, estrategias de difusión y fidelización, etc.), planteándose en la línea de una necesidad del desarrollo de competencias específicas y de su profesionalización ${ }^{13}$.

En lo que concierne a su discurso público, este se ha ido articulando y recreando al paso de una trayectoria dinámica, que se retroalimenta de los propios espacios generados. Se trata de un discurso centrado en la bibliodiversidad ${ }^{14}$, que estos editores conciben como la aplicación de la diversidad cultural al mundo del libro, de

10 Los materiales movilizados en este texto se basan en el conjunto de entrevistas que componen nuestra investigación, las cuales fueron realizadas entre 2009 y 2012.

11 Por ejemplo, la editoriales Lom y Ril Editores, son las únicas en contar con su propia imprenta, ofreciendo servicios gráficos y de impresión a otras pequeñas editoriales, a clientes particulares y a diversas instituciones del Estado.

12 La Furia del libro corresponde a un colectivo de pequeñas editoriales que comenzaron a organizarse el año 2009, en torno a la realización de una Feria del libro independiente. Estas se dedican fundamentalmente a la publicación de autores jóvenes, en particular poesía, "libros objeto", narrativa, crítica social y un segmento de obras experimentales, como también a la traducción específica de textos que rescatan autores olvidados. Un rol destacado en la visibilización de esta agrupación ha jugado el editor Galo Ghigliotto (Editorial Cuneta).

13 Que es aún bastante débil en Chile, contribuyendo a ello una ausencia prácticamente total de carreras o formaciones ligadas a esta profesión.

14 Si bien es muy difícil fijar con exactitud el momento de emergencia de un término, al rastrear en varias fuentes y presentaciones académicas y asociativas, los orígenes del término "bibliodiversidad" nos llevan a Chile. Su aparición se remontaríaa mediados de los años noventa, cuando uno de los editores de Ril, inspirándose del concepto de biodiversidad comparó lo que sucedía en el ambiente editorial con el Ilamado "desierto verde", como se denomina a las rentables plantaciones de pino que arrasan el bosque nativo y [su] "biodiversidad". (Fuente: www. rileditores.cl). Este término ha alcanzado una larga difusión internacional (alojado en EDIN y luego irradiado por Editores Independientes en Gijón), instalándose como uno de los términos clave al interior del lenguaje en común movilizado por los editores independientes a nivel mundial. 
la cual se consideran sus garantes. Asimismo, exhiben un posicionamiento respecto a la necesidad de contar con intercambios más equilibrados, para lo cual demandan una mayor participación del Estado a través de la generación de políticas públicas y de medidas destinadas a la protección de la cultura y el libro en particular. Al momento de su creación, los editores independientes declaraban:

"Nos sentimos motivados por el carácter asociativo de Editores de Chile, es una manera de oponernos a la lógica de concentración económica. Nos sentimos motivados por las iniciativas conjuntas tendientes a proteger la bibliodiversidad, la heterogeneidad, la diversidad cultural, la creación de un sentido que trasciende la rentabilidad. Nos sentimos motivados por la consolidación de una industria chilena del libro, con el cuerpo y el alma que tienen estos libros" (EDIN, 2000).

El extracto ilustra como EDIN comienza a apropiarse desde temprano de algunas de las principales categorías que configuran el lenguaje internacional de los editores independientes, traduciéndolas a la escena local. Esta reinscripción discursiva es alojada en la diversidad de expresiones culturales que para ellos representa la industria chilena del libro, amenazada por una vertiente de producción "estandarizante", encarnada por los grandes grupos trasnacionales de la edición. De esta manera "edición independiente" se declina en "edición nacional", siendo movilizada como identidad(es)/representación(es) que se definen en oposición a una "edición de conglomerados" de carácter "transnacional"15.

Asimismo, se posicionan - desde un espacio de resistencia colectiva- contra una lógica "puramente económica" que considera al libro como "una mercancía como cualquiera otra”, sin reconocer la doble conformación (física y espiritual) que a su juicio él posee. Al mismo tiempo, comienza a esbozarse una discusión acerca de un estatuto particular para los bienes culturales en Chile.

La diversidad cultural de la cual ellos se sienten "defensores naturales" es aquí concebida como una barrera o dispositivo de protección de los pequeños productores de la cultura. Se expone entonces un elemento interesante de notar si consideramos que se trata de empresarios, pequeños y medianos, que rebasan su vocación comercial primera, auto asignándose una función moral, ciudadana y patrimonial. De esta manera, estos editores dan cuenta de la manera en que se perciben y se (re)

15 Andre Schiffrin (2005) describe, desde el punto de vista de un editor independiente, las diferentes dinámicas bajo las cuales se produce el fenómeno de concentración: ya sea ligadas a un proceso de crecimiento acelerado de los conglomerados locales (caso alemán), al desarrollo de grandes grupos transnacionales, que corresponde a la situación de América latina (consorcios fundamentalmente de propiedad española), o casos complejos como el Ilamado "affaire Vivendi" en Francia, en cuya adquisición convergieron múltiples elementos e intereses. 
presentan, como actores que privilegian la índole cultural del libro al que consideran un instrumento formador decisivo ${ }^{16}$.

Finalmente, existe otro elemento que aporta un rasgo acerca de lo que este colectivo piensa de sí: una comprensión del rol del editor como un "constructor cultural”, al cual le otorgan un valor ligado a su independencia, a la estética de las obras, y a la posibilidad de hacerlas públicas:

"Nosotros creemos que es fundamental mantener vivo un ethos de trabajo editorial, donde el valor de nuestra tarea reside en la obra creada, en el libro publicado, en el encuentro del lector con el texto, y no solamente en el posible beneficio comercial"(Manifiesto Editores independientes de Chile, 2003, p. 1).

\section{ASOCIATIVISMO A MÚLTIPLES NIVELES}

El sector de la edición independiente chilena se ha caracterizado desde sus orígenes por la construcción de redes a múltiples escalas, una política de alianzas entre pares, que ha ido instituyendo espacios de intercambio de manera sostenida en el tiempo. Se trata de redes que aseguran una amplia circulación de la información y la proyección de acciones colectivas, así como la capacidad de producir una reflexión sobre sí mismos. Estas dinámicas de participación se revelan como centrales para observar su construcción de notoriedad sobre la escena nacional e internacional.

Un antecedente que, si bien no explica todas las aristas de su participación, nos ayuda a comprender las bases de esta capacidad organizativa, se encuentra en el hecho que varios de sus miembros habían pertenecido a colectivos del mundo social durante la dictadura (trabajo con mujeres pobladoras, agrupación de familiares de presos políticos, asociación de fotógrafos independientes, comités de solidaridad con Chile en el exilio, etc.). Estas experiencias y aprendizajes les hacen portar ciertas competencias o habilidades sociales de trabajo mancomunado que, a nuestro juicio, estos editores reinscriben al seno de una asociación profesional de la cultura.

La proliferación de un conjunto de encuentros ${ }^{17}$, foros y seminarios realizados en distintos países, a partir de fines de los años noventa, así como la posibilidad de acceder a espacios de difusión mayor (como las ferias del libro) permite que un grupo

16 "Concebimos el libro como fuente y vehículo cultural y educativo, constructor de identidades, soporte de pluralidad y diseminador de diversidad" (EDIN, 2000)

17 Desde el Primer Encuentro de Editores independientes (Gijón, 2000), Madrid (2001), Dakar (2003), el Primer encuentro de editores independientes Los editores independientes de/ mundo latino y la Bibliodiversidad (Guadalajara, 2005), pasando por Congreso del Grupo Interamericano de Editores (Madrid, 2006), al Seminario internacional Hacia una política de integración del Libro latinoamericano(Santiago, 2007), entre otros. 
de pequeños editores comiencen a coincidir, a producir diálogos e intercambiar diagnósticos. A lo largo de estas instancias, soporte material de creación de nexos, empieza a madurar la idea de organizarse conjuntamente. Así surge, en 1998, Editores Independientes, un primer referente regional que reúne cuatro editoriales independientes: Lom (Chile), Era (México), Trilce (Uruguay) y Txalaparta (País Vasco, España), una cuadrilla ${ }^{18}$ que continúa un trabajo hasta la actualidad, sobre la base de un conjunto de elementos compartidos (visión, discurso, maneras de trabajar, herramientas de difusión y posicionamiento editorial) y al desarrollo de una experiencia de coedición, que a la fecha alcanza los 70 títulos conjuntos. Pablo Harari, de Ediciones Trilce, lo relata de la siguiente manera:

"Por un lado hay intercambios de experiencias interesantes y conocimientos, y de problemas, de desafíos y de errores; por otro lado hay intercambios de títulos y también de lo que podíamos salir a descubrir para editar en conjunto. Eso nos obligó también a buscar los mecanismos ... hicimos reglas flexibles, políticas flexibles, con reglas basadas en un espíritu solidario colaborativo discutidas en conjunto, con aranceles diferenciados según el tamaño (porque entre nosotras cuatro hay tamaños y mercados distintos). Por ejemplo, compartiendo costos de traducción” (Entrevista Pablo Harari, octubre 2012).

La posibilidad de verse a la luz de la situación, y las experiencias recorridas por sus pares, va transformando la propia manera en que estos actores se concebían en sus contextos nacionales, así como del lugar que ocupa la edición independiente a nivel mundial; complejizando sus diagnósticos y abriendo otras perspectivas.

En esta dirección, y a partir de esta primera experiencia asociativa regional, surge la idea de replicarlo a nivel local ${ }^{19}$. Precisamente en ese momento algunas editoriales nacionales comienzan a reunirse por primera vez, al surgir una posibilidad de postular a un Profo ${ }^{20}$ llamado "Consorcio para exportadores de libros de Chile”. Este consistía en un proyecto que ofrecía Corfo entre sus líneas de fondos concursables, el cual

18 Es el nombre con el que ellos mismos se refieren al colectivo.

19 En este impulso resulta central la participación de los editores de Lom, Paulo Slachevsky y Silvia Aguilera, quienes formarán parte activa de la generación que lidera la estructuración del mundo de la edición independiente en Chile. Slachevsky es elegido presidente de EDIN durante dos períodos (2000-2004), destacándose como una figura con una importante capacidad de reagrupamiento de sus pares para la articulación de un actor colectivo, tomando la palabra pública a favor del libro chileno y la bibliodiversidad. En 2005 recibe la medalla de oficial de las Artes y las letras, otorgada por el Ministerio de cultura de Francia, donde se destaca su participación en la defensa de la diversidad cultural. Para una visión más completa acerca del papel jugado por Lom véase Symmes (2009).

20 Profo significa Proyectos asociativos de fomento y corresponde a una de las líneas de trabajo desarrolladas por Corfo. En este marco, este grupo de editores presentó un proyecto para crear una distribuidora. 
requería contar con un número determinado de editores interesados para poder presentarse. De esta forma, la postulación genera las condiciones para ir pensando en planear una plataforma en común, que en ese momento estaba lejos de ser el espacio asociativo que devino posteriormente.

Es así como se crea a fines de los noventa la Asociación de Editores Independientes de Chile, siendo la primera en su género en América latina. Fundada sobre la base del reagrupamiento de siete editoriales (Lom, Cesoc, Cuarto Propio, Cuatro Vientos, Dolmen, Pehuén y Ril), a las que luego se suman Universitaria y Andrés Bello, para tomar en 2003 su actual nombre: Editores de Chile ${ }^{21}$, Asociación de Editores Independientes, Universitarios y Autónomos. Mencionaremos que este colectivo fue creciendo progresivamente, pasando de contar con 17 miembros -en 2005-a 42 en 2007 y a cerca de 50 en la actualidad. Este nuevo polo de actores se estructura en torno a la movilización del ideario de un "libro chileno" y la necesidad de desarrollar una "industria nacional del libro", definiendo una identidad en contraposición a la Cámara chilena del libro, que hasta ese momento era la única instancia federativa de los editores.

Fundada en 1950, la Cámara es una asociación gremial que reúne empresas editoriales, distribuidoras de libros, librerías, organizaciones de venta directa y casas editoriales trasnacionales con sede en Chile. Goza de un importante prestigio ligado a su antigüedad y a la relación que mantiene con los grandes grupos. La Cámara ha focalizado su labor fundamentalmente en la organización anual de la Feria del Libro de Santiago - evento de gran envergadura y popularidad en la escena nacional- así como en la persecución de la piratería ${ }^{22}$ (problema que les afecta directamente a causa de la reproducción de los best sellers, producidos casi en su totalidad por los grandes sellos editoriales). En este sentido, este nuevo referente va a producir reordenamientos al interior del espacio editorial, generando un contrapeso y disputándole a la Cámara la representación exclusiva de los editores. El editor de Pehuén, Sebastián Barros, relata en la cita que presentamos más abajo, la manera en que se produce una escisión, el año 2001, al momento en que nueve editoriales que hasta entonces participaban de ambas instancias ${ }^{23}$ deciden retirarse:

\section{En adelante EDIN.}

22 Impulsando proyectos de ley, así como el desarrollo de un trabajo con la policía y organismos de investigación y persecusión de la piratería.

23 Salvo Lom, todas pertenecieron en algún momento a la Cámara. En septiembre de 2001, esta última convoca a una asamblea a fin de modificar un artículo de los estatutos para impedir esta doble filiación de los miembros pertenecientes al estamento de editores. 
"Queremos que se abra la posibilidad de conversar el tema del libro en forma franca, abierta, con todos los matices que eso tiene. Intentamos hacer esto por años con la Cámara chilena del libro y siempre éramos minoría y nunca lográbamos hacer nada. Entonces, lo que hemos logrado hacer en torno a esto lo hicimos por fuera" (Boletín + Ojos para el Libro chileno, 2006, p. 10).

Producto de esta situación se explicita la existencia de intereses distintos. El grupo de editores que abandona la Cámara comienza a configurar un espacio diferencial, invirtiendo recursos simbólicos en ser reconocido como tal por las autoridades. Bajo el desarrollo de un trabajo sostenido en el tiempo y levantando el label de la "industria editorial nacional del libro" logran en 2007 tener una representación en el Consejo nacional del libro, bajo un acuerdo tácito donde la Cámara representaría a los distribuidores y la Asociación de Editores Independientes a los editores.

Siempre en la dirección de un desarrollo progresivo de redes, los editores independientes ampliarán su presencia hacia un circuito internacional, incorporándose el año 2002 a la Alianza internacional de Editores Independientes ${ }^{24}$. Toda esta paulatina formalización de su actividad asociativa les permitirá ir generando estrategias colectivas para enfrentar las dificultades presentes en un escenario de globalización editorial y de "desprofesionalización del oficio de editor". Estas estrategias son proyectadas a partir de un análisis que pretende "dar cuenta de la diversidad de cada contexto pero poniendo el acento en los elementos unitarios necesarios para la acción” (Alliance des éditeurs, 2005, p. 6). En efecto, más allá de las disimetrías entre los cuadros regulatorios de la cultura en cada país, el trabajo en redes les provee concretamente de un repertorio de herramientas comunes, que van desde: cifras, diagnósticos, líneas programáticas de trabajo, materiales jurídicos, propuestas legislativas, hasta la construcción de un lenguaje y un aparato conceptual compartido.

Mediante la participación sostenida en esta plataforma de informaciones, constatan que comparten una mirada similar acerca de las lógicas de funcionamiento del mercado de la edición, así como de una cierta concepción del libro y del lugar central que a este se le debiese atribuir en la sociedad. Esta red hace posible la fabricación sucesiva de elementos para pensarse desde una visión multifocal, esto es: tanto del propio lugar que detentan en el espacio cultural nacional, como de la posición que la edición independiente ocupa a nivel mundial. Sumado a esto, los intercambios con figuras emblemáticas de la edición independiente como el editor

24 La Alianza internacional de editores independientes constituye el referente mundial de la edición independiente. Con sede en Paris, fue creada en 2002 y está estructurada por áreas lingüísticas, representando cerca de 400 editoriales de cerca de 50 países. "Editores Independientes" fue el primer colectivo de editores en hacerse parte de la Alianza. En la actualidad, el área hispanohablante es coordinada por el editor chileno Juan Carlos Sáez. 
franco americano André Schiffrin ${ }^{25}$, van a ir reforzando la identidad de este colectivo en su dimensión internacional, cimentando poco a poco lo que ellos definen como el "movimiento de la edición independiente".

\section{SECUNDARIOS, PERO CENTRALES: LA MOVILIZACIÓN DE UNA CONDICIÓN COMPLEJA}

El posicionamiento progresivo de los editores independientes sobre la escena pública se produce a través de repertorios de acción desarrollados de manera duradera en el tiempo: elaboración de manifiestos, documentos, boletines de difusión y propuestas técnicas que hacen circular en múltiples espacios. Gestionan reuniones con senadores y responsables políticos del ámbito de la cultura, envían cartas a las autoridades exponiendo su posición respecto a problemáticas concretas, las que sitúan cada vez dentro de la temática mayor del Libro y la lectura chilenos ${ }^{26}$ : una Carta abierta al presidente Lagos, abogando por un IVA diferenciado para el libro, en 2005; otra dirigida a la presidenta del INE, en 2006, donde piden la incorporación del libro a la encuesta de consumo de hogares y del Censo nacional. Adicionalmente, desarrollan un estudio llamado "El libro chileno no es caro", donde con una muestra basada en una lista de 21 editoriales y 3554 títulos $^{27}$, deslindan la presencia de un libro chileno a precio accesible en una clara alusión a los precios de los títulos que en el mercado nacional presentan los libros producidos por las grandes editoriales. En estos distintos documentos se aprecia la conformación paulatina de un lenguaje en común, que se apoya en categorías y experiencias pertenecientes a una "comunidad

25 André Schiffrin (Paris, 1935) proviene de una familia que emigra a EEUU huyendo de persecuciones antijudías. Dirigió largos años la editorial Pantheon Books, cofundada por su padre, Jacques Schiffrin, en 1941 (fundador igualmente de La Pléiade en 1923). Es la editorial que publicará a Sartre, Chomsky y Foucault, entre otros. Después de ser adquirida en los 80 por un gran conglomerado, Andre Schiffrin funda la editorial New Press. Es autor de L'édition sans éditeurs (1999), Le contrôle de la parole (2005) ambas publicadas por La fabrique. Schiffrin es invitado permanente de encuentros y reuniones. Entre otros al Encuentro de Gijón el año 2000 y al Seminario "Hacia una política de integración del libro latinoamericano: Políticas públicas, Concentración y Bibliodiversidad", realizado en Santiago -Centro Cultural Palacio de La Moneda- en 2007.

26 Este es un elemento interesante de analizar por cuanto no elaboran petitorios ni reivindicaciones gremiales. La manera de exponer las problemáticas responde a una visión de ellos como sector cultural integral, auto concibiéndose como representantes de la sociedad civil.

27 Este estudio dialoga con una de las razones que se esgrimen para el bajo interés del público chileno hacia la lectura, a saber: el ser muy caro e inaccesible. Dentro de los datos más importantes está que el precio público del libro (con IVA) es de $\$ 6.896$ (US $\$ 12,7$ ) y el precio público (sin IVA) es de $\$ 5.795$ (US\$10,7). Realizado en 2001 por el editor Juan Carlos Sáez con el apoyo de ProChile, constituye el único estudio estadístico que existe hasta la actualidad acerca de la realidad editorial chilena. Cabe destacar que la ausencia de cifras es uno de los principales problemas con que nos encontramos quienes trabajamos en este campo de investigación. 
editorial internacional" de las cuales ellos se apropian, adaptándolas a su contexto local: propuesta de un IVA diferenciado para el libro de un $7 \%^{28}$, precio único, bibliodiversidad, necesidad de políticas equilibradas para el libro, necesidad de una red de transporte y distribución, reforzamiento de las industrias editoriales de los países del sur, circulación desigual de los bienes culturales en el mundo, necesidad de un circuito de librerías y bibliotecas, entre otras.

La gestión de diferentes capitales: simbólico - a partir de su cercana relación con los autores e intelectuales ${ }^{29}$, quienes les incitan constantemente a reanudar sus lazos con los orígenes del campo editorial-, la obtención de premios y reconocimientos, el desarrollo de textos que resguardan la calidad a un precio abordable o la participación en ferias), social (las redes del mundo asociativo) y una cierta acumulación de legitimidad, producto de sus modos organizativos (fortaleciendo los espacios colectivos) les fue permitiendo paulatinamente abrirse campo en el ámbito de su relación con el Estado, modificando el curso del espacio político de la edición.

Por otra parte, su acceso a lo internacional se efectúa a través del mundo asociativo, tanto en su dimensión simbólica (la internacionalización de su discurso) como orgánica (profesional y federativa) al hacerse parte de los circuitos y debates internacionales de fuerte actualidad. Estas dinámicas van conformando una clave de legitimación ante los responsables políticos de la cultura en Chile.

Al observar la fundación de la Asociación Editores de Chile en clave internacional, interrogamos en qué medida las lógicas y dinámicas del nuevo paisaje global del libro se revelan en las maneras de organizarse (y de intervenir públicamente) de un colectivo nacional de editores. Para abordar su trayectoria, nos concentraremos brevemente en dos episodios de su accionar que nos permiten ilustrar la movilización de sus capitales: sobre el plano local, los modos organizativos desplegados en la estructuración de un nuevo polo de actores, que junto con producir reordenamientos sobre el espacio editorial más largo, cumplen una función de mediación entre los campos político y cultural. Sobre la esfera internacional: describiendo la inscripción progresiva del mundo de la edición independiente chilena en un circuito internacional, cuyo eje mayor ha sido la movilización del concepto de diversidad cultural.

En el contexto local, son parte activa en la generación de la Mesa por el libro, instancia que resultó clave para hacer avanzar los debates que darán cuerpo a la Política nacional del libro y la lectura. Bajo la organización de la Fundación Chile 21, la primera versión de esta reunión se realizó en 2001, con la participación de diversos actores (representantes editoriales nacionales y extranjeras asentadas en Chile, distribuidoras, librerías y autores, la Cámara, Editores de Chile, el Consejo nacional

28 Chile es uno de los pocos países que no aplica un IVA diferenciado para el libro.

29 Lo cual constituye su capital principal. 
del Libro y otros expertos del sector público), produciendo la "Propuesta Pública N 5 : Acceso al libro y fomento a la lectura”, que se entregó al gobierno el año 2002, pero sin lograrse avances significativos en su implementación. Unos años más tarde, en 2005, este trabajo es retomado bajo la coordinación de Ricardo Brodsky ${ }^{30}$, arrojando como resultado el documento "Una política de Estado para el libro y la lectura”. Destacamos que las propuestas aquí presentadas son recogidas casi a cabalidad en la política lanzada en $2006^{31}$.

El tipo de relación que los editores sostienen con el Estado se da bajo una dinámica en la que éstos permanentemente están generando y/o reacomodando espacios existentes, de manera de poder garantizar su participación en los debates públicos. Levantan estrategias de posicionamiento colectivo participando de manera activa en las diversas instancias institucionales donde se aborda el tema del libro, la lectura y el acceso a los bienes culturales, muchas veces impulsadas por ellos mismos.

Una segunda esfera corresponde a la inscripción creciente de este sector en un circuito internacional de la cultura, cuyo eje principal ha sido la aparicióny movilización del concepto de diversidad cultural. El mundo de la edición independiente chilena va a jugar un papel medular en la creación de la Coalición chilena por la diversidad cultural (CDC), destacando como un actor capaz de reunir y configurar un espacio de acción junto a otras asociaciones de la cultura. Como explicaremos brevemente, su funcionamiento de estilo colectivo, con capacidad de establecer vínculos a múltiples escalas, sumado a la dinámica de militancia cultural ${ }^{32}$ que venían desarrollando, los sitúa como portadores de un capital simbólico. Capital que les permitirá liderar este espacio, abriendo y promoviendo un debate hasta ese momento inexistente en Chile.

30 Ricardo Brodsky fue asesor del primer ministro de Cultura del CNCA, José Weinstein. Igualmente se ha desempeñado como coordinador interministerial durante el gobierno de Michelle Bachelet y es en la actualidad director del Museo de la Memoria y de los Derechos Humanos.

31 A modo de breve cuadro institucional: en 1993, en los albores del retorno a la democracia se crea el Consejo y el Fondo nacional del libro y la lectura (ley 19.721). En los años venideros el libro no ocupó verdaderamente un lugar central ni en los programas de gobierno ni en las políticas culturales, sino hasta 2006, con la presentación de la Política nacional del libro y la lectura. No obstante, debemos señalar que se desarrollaron una serie de iniciativas, especialmente bajo la gestión de Clara Budnik a la cabeza de la DIBAM, destinadas a ampliar un público lector: "Chile quiere leer", el "Casero del libro", proyectos de colaboración público-privada como "Bibliometro", o más recientemente el "Maletín literario", junto con la construcción de un número significativo de bibliotecas en las dos últimas décadas (pasando de 200 a casi 450).

32 Con esto queremos decir que se trata de una suerte de "militancia cultural" que ellos abordan bajo lógicas de trabajo profesional y asociativo. 
El Primer encuentro de asociaciones profesionales de la cultura ${ }^{33}$ celebrado en Montreal, en 2001, constituye un antecedente fundamental para la creación de la CDC. Es a partir de esta reunión, que tuvo como columna vertebral la temática de la diversidad cultura ${ }^{34}$, que estas asociaciones ponen a circular una visión acerca de la necesidad de un estatuto diferencial para los bienes culturales. Así, directamente a su regreso a Chile, en octubre de 2001, deciden fundar la Coalición chilena por la diversidad cultural ${ }^{35}$, eligiendo al editor Paulo Slachevsky como presidente. Desde esta plataforma comienzan a propagar los debates entablados en Montreal y a demandar, por diversos medios (Cartas abiertas a los responsables políticos, declaraciones, etc.), un tratamiento particular para la cultura en el marco de las negociaciones de los tratados de libre comercio. La Coalición presenta la diversidad cultural como un asunto de interés público y nacional y demanda una participación más enérgica del gobierno en el resguardo de la cultura, a través de políticas públicas. Es la apropiación, con un anclaje local, de este "discurso legítimo" gestado al seno de la Unesco, que les permite interpelar a su propio Estado.

Para el caso chileno, con un escenario de fuerte apertura económica ${ }^{36}$ emprendida durante los gobiernos democráticos, el ingreso de la cuestión de la diversidad cultural a la agenda política se hace posible al coincidir con la última ronda de negociaciones del TLC con EE.UU, a cargo de Direcon ${ }^{37}$. Este contexto de negociaciones ya bastante avanzadas se presenta como una ventana de oportunidad sin precedentes para la Coalición, por tratarse de un espacio que se encontraba ya operando con determinados plazos. Es precisamente la emergencia -en un primer momento- de la categoría de "excepción cultural" que más tarde desembocaría en el principio de diversidad cultural ${ }^{38}$, el proceso que vino a evidenciar la tensión entre cultura y mercado.

\footnotetext{
33 Organizado por la Coalición canadiense, con el apoyo del Ministerio de cultura que dirigía Sheila Copps, contó con la participación de 60 asociaciones de la cultura venidas de 50 países. Este encuentro constituye un antecedente fundacional en la gestación de las coaliciones por la diversidad cultural a nivel mundial. En el caso chileno, son cuatro las organizaciones que participan: Sidarte, representado por Mané Nett; Sindicato Nacional de Trabajadores de la Música de Chile, por Nano Acevedo; Asociación de Productores de Cine y Televisión de Chile, por Bruno Betatti; y la Asociación de Editores independientes, por Paulo Slachevsky.

34 Para una lectura en profundidad acerca del surgimiento del concepto y los debates en torno a la diversidad cultural véase Bustamante (2007).

35 En adelante CDC.

36 Chile ha firmado hasta la fecha 22 Acuerdos comerciales con 59 países. Fuente: www.direcon. gob.cl

37 Dirección de Relaciones Económicas del Ministerio de Relaciones Exteriores de Chile.

38 Plasmado, luego de un largo proceso, en la Convención por la diversidad cultural de la Unesco, del año 2005.
} 


\section{A MODO DE CONCLUSIONES}

El proceso de transición hacia la democracia - como escenario interno-así como la existencia de un espacio editorial reconfigurado - a nivel internacional-confluyen en la generación de un nuevo panorama en el que los editores independientes chilenos van a situarse, definirse y elaborar sus estrategias de resistencia. Es en este nuevo contexto político, económico, social y cultural específico donde estos actores van a construir su catálogo y desarrollar su quehacer.

El sector de la edición independiente se ha organizado como una respuesta frente a una doble situación. Por una parte, los desafíos que instala en la actualidad un mercado mundial del libro (a la vez concentrado de más en más y ampliamente diversificado) y por otra, la existencia de un cuadro institucional todavía bastante precario en lo que respecta a las políticas del libro en Chile. En este sentido, su accionar en la esfera pública puede ser leído en clave de resistencia cultural, produciendo un discurso y una práctica que - desde una posición no central-utiliza la independencia como un recurso de interpelación simbólica, que alcanza efectos políticos. A su vez, la adquisición de una cierta legitimidad como resultado de su manera de actuar (fortaleciendo los espacios colectivos) fue fraguando un nuevo actor que en los últimos veinte años se ha constituido como indispensable para comprender la vehiculización y el ingreso de categorías como diversidad cultural y bibliodiversidad al interior del debate cultural en Chile.

La doble y paradojal condición exhibida por los editores independientes sobre la escena nacional, los sitúa en una posición heterodoxa. Por un lado secundarios, en cuanto a su peso económico y financiero (aun cuando ocupan una franja no menor del mercado del libro chileno), y a la vez determinantes sobre el plano simbólico. Ello, respecto a la función que cumplen resguardando un ámbito de cuidado estético y de búsqueda de autonomía de campo. Las editoriales miembro de Editores de Chile pertenecen a un campo de producción restringida (Bourdieu, 1999), cuyo valor está ligado al pluralismo y la naturaleza de las obras publicadas. Se trata de actores complejos que cumplen a la vez un rol de agente económico, en tanto pequeños empresarios de la cultura, pero al mismo tiempo moral y cultural.

Es desde esta condición dual donde ellos se posicionan, en una operación que utiliza el margen como un espacio de resistencia de carácter transnacional. El sector de la edición independiente va a cumplir una función revitalizante, en lo que concierne la instalación de la problemática del libro y la lectura como un debate público; convirtiéndose en definitiva en actores que van a conectar permanentemente los campos cultural y político, operando como mediadores.

Sobre la arena cultural local se constituyen en catalizadores que hacen cambiar las reglas del juego, adoptando una estrategia de legitimación a partir de la apropiación de un discurso internacional. Su trayectoria nos permite observar la manera en 
que los actores desarrollan estrategias de sobrevivencia, que se apoyan en cruces complejos entre lo local y lo internacional. Es presentándose con un discurso que los responsables del Estado perciben como "legítimo", que estos actores pueden dirigirse a las autoridades. De este modo, traducen sus planteamientos y problemáticas específicas como sector cultural, reinscribiéndolos en el contexto nacional. En este sentido, el caso de la Asociación de Editores independientes de Chile nos invita a pensar hasta qué punto la independencia constituye un asunto transnacional.

\section{Referencias bibliográficas}

Aguilera, S. (2002). Claridades y experiencias en Madrid. Rocinante, 50, 26-27.

Alliance des éditeurs indépendants. (2006). Des paroles et des actes pour la bibliodiversité. Paris.

Boletín + Ojos para el Libro chileno. (2006). Dada la débil situación en la que se encuentra el libro chileno, debemos luchar fuerte por ello (pp. 10-12). Santiago de Chile.

Bourdieu, P. (1991). Le champ littéraire. Actes de la recherche en Sciences Sociales, $89(89), 3-46$.

Bourdieu, P. (1999). Édition, Éditeurs (1) Une révolution conservatrice dans l'édition. Actes de la recherche en Sciences Sociales, 126/127, 3-28.

Bourdieu, P. (2002). Les conditions sociales de la circulation internationale des idées. Actes de la recherche en Sciences Sociales, 145, 3-8.

Bustamante, M. (2007). Ladoption de la diversité culturelle. Analyse sociologique d'une stratégie de légitimation culturelle. Tesis para optar al grado de Magister en sociología, EHESS, París.

Cárdenas, J. P. (2006). El periodismo y el proceso político chileno. En Zapata, F. (Ed.), Frágiles suturas (pp. 479-488). México, DF: El Colegio de México.

Castells, M. (2005). Globalización, desarrollo y democracia: Chile en el contexto mundial. Santiago de Chile: Fondo de Cultura Económica.

Dezalay, Y. y Bryan, G. (2002). La internacionalización de las luchas por el poder. Santiago de Chile: ILSA- Universidad Bolivariana.

Douyère, D. y Luc, P. (2008). L ' accès à la parole: la publication politique des éditeurs indépendants. Communication et langages, 156, 75-89.

Editores de Chile. (2000). Tríptico institucional.

Fundación Chile 21 y Editores de Chile. (2005). Una política de Estado para el libro y la lectura. Estrategia integral para el fomento de la lectura y el desarrollo de la industria editorial en Chile. Santiago.

Garretón, M. (1995). Hacia una nueva era política. Santiago de Chile: Fondo de Cultura Económica. 
Garretón, M. (2006). Del pinochetismo a la sociedad democrática. Santiago de Chile: Random House Mondadori.

Guzmán, J. (2007). Carta por el libro. Santiago de Chile: Lom.

Legendre, B. y Robin, C. (2005). Figures de l'éditeur. Paris: Nouveau Monde.

Legendre, B. (2007). Quel avenir pour les éditeurs de tailles moyenne et petite ?.En Mollier, J. Y. (Dir.), Où va le livre? (pp. 69-90). Paris: La Dispute.

Moulian, T. (1993). Démocratie de consensus ou démocratie des conflits. Problèmes d'Amérique latine, 11, 17-23.

Noël, S. (2009). La petite édition indépendante face à la globalisation du marché du livre : Le cas des éditeurs d'essais «critiques ». En Sapiro, G. (Dir.), Les contradictions de la globalisation éditoriale (pp. 133-156). Paris: Nouveau monde.

Sapiro, G. (2009). Les contradictions de la globalisation éditoriale. Paris: Nouveau Monde.

Schiffrin, A. (1999). L 'édition sans éditeurs. Paris: La Fabrique.

Schiffrin, A. (2005). Le contrôle de la parole. Paris : La Fabrique.

Sorá, G. (2009). Des éclats du siècle: unité et désintégration dans l'édition hispanoaméricaine en Sciences sociales. En Sapiro, G. (Dir.), Les contradictions de la globalisation éditoriale (pp. 93-116). Paris: Nouveau Monde.

Sorá, G. (2008). Edición y política: Guerra fría en la cultura latinoamericana de los años 60. Revista del Museo de Antropología, 1, 97-114.

Subercaseux, B. (2000). Historia del libro en Chile (Alma y cuerpo). Santiago de Chile: Lom. 